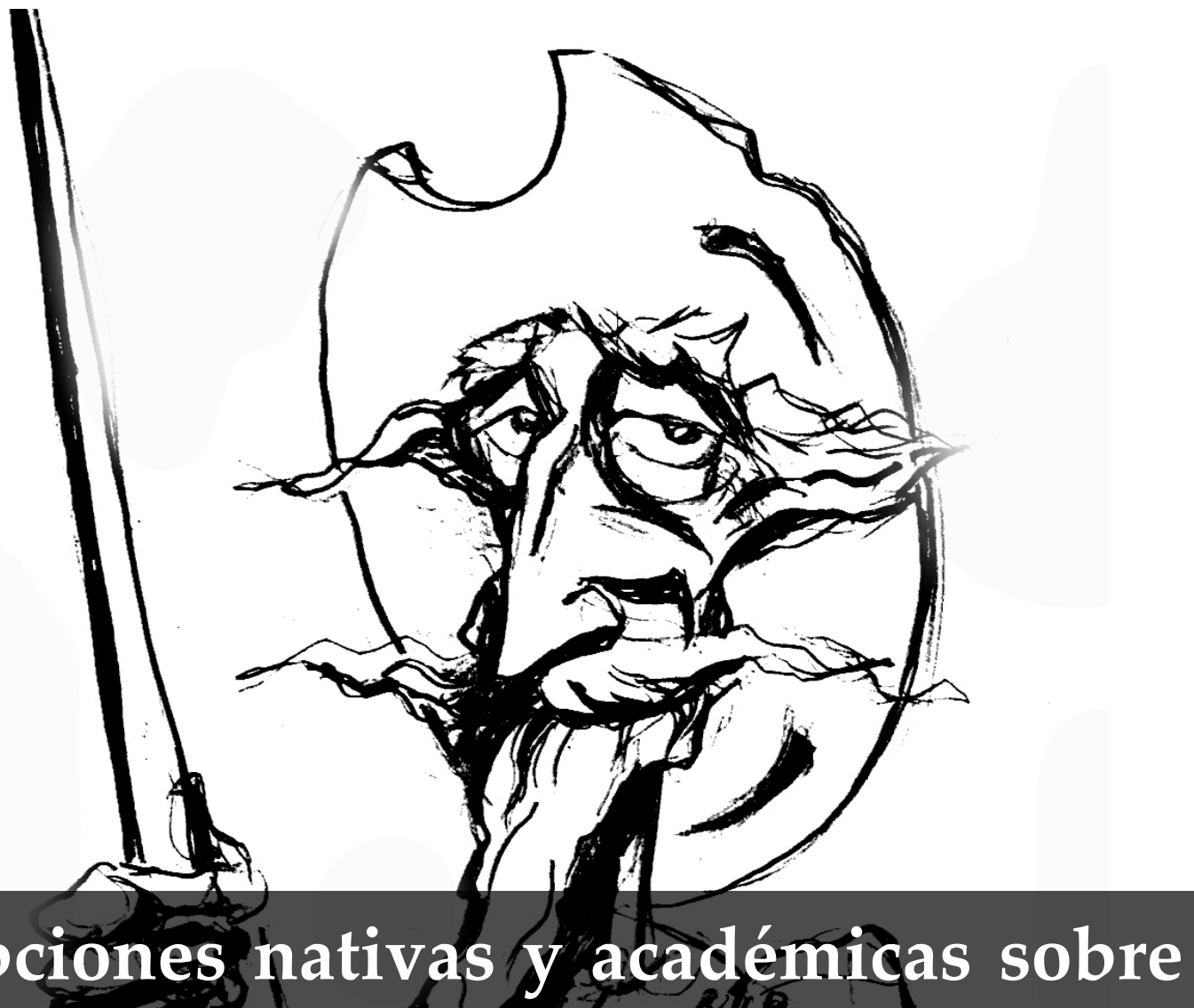

Concepciones nativas y académicas sobre los partidos políticos modernos. Reflexiones en torno al estudio del Partido Socialista argentino.

[Gonzalo Cabezas] 


\title{
Concepciones nativas y académicas sobre los partidos políticos modernos. Reflexiones en torno al estudio del Partido Socialista argentino
}

\author{
Native and academic conceptions about the modern political parties. \\ Reflections around the study of the Argentinian Socialist Party
}

GonZalo E. CABEZAS

\begin{abstract}
Resumen
Este artículo analiza concepciones nativas y académicas sobre los partidos políticos modernos en Argentina. Por un lado, rastreamos las características que según la visión de los dirigentes socialistas de comienzos de siglo $X X$ debía tener un partido para ser considerado moderno. Por otro, observamos cómo importantes figuras del campo académico, desde su pertenencia política socialista, construyeron una mirada normativa de los partidos modernos que guardó ciertas similitudes con la concepción nativa. Por último, recuperamos los estudios sobre las prácticas políticas como vía para repensar la política desde sus formas concretas y no desde visiones prescriptivas cuyos supuestos no se explicitan.
\end{abstract}

Palabras clave: partidos políticos modernos Partido Socialista - concepciones nativas concepciones académicas - prácticas políticas

\begin{abstract}
This article analyzes native and academic conceptions about modern political parties in Argentina. On one hand, we trace the characteristics that according the vision of the socialist leaders from the beginnings of the twentieth century had to have a party to be considered modern. On the other hand, we observe how important figures of the academic field, from their socialist political background, constructed a normative view of the modern parties that was similar to the native conception. Finally, we retrieve the studies about political practices as a way to rethink politics from concrete experiences rather than from prescriptive visions which assumptions are not explicit.
\end{abstract}

Keywords: modern political parties - Socialist Party - native conceptions - academic conceptions - political practices

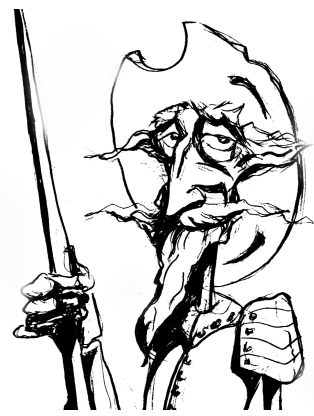

Recibido con pedido de publicación el 30 de abril de 2016

Aceptado para su publicación el 19 de octubre de 2016

Versión definitiva recibida el 21 de noviembre de 2016

Gonzalo E. Cabezas, Universidad Nacional del Sur / Consejo Nacional de Investigaciones Científicas y Técnicas, Argentina; e-mail: gonzacabezas@gmail.com

Esta obra se publica bajo licencia Creative Commons. Atribución-NoComercial-CompartirIgual 4.0 Internacional

Cabezas, Gonzalo E. “Concepciones nativas y académicas sobre los partidos políticos modernos. Reflexiones en torno al estudio del Partido Socialista argentino", Prohistoria, Año XIX, núm. 26, dic. 2016, pp. 53-75. 


\section{Introducción}

Algunos años atrás inicié una investigación sobre el Partido Socialista (PS) en la primera mitad del siglo XX. ${ }^{1}$ En las primeras aproximaciones al tema llevé a cabo una serie de lecturas sobre los partidos políticos en general y sobre el PS en particular, enfocando mi atención en la estructura organizativa y en las prácticas políticas de los militantes. A medida que consultaba dicha bibliografía, comencé a percatarme de que en general estaba atravesada por ciertos supuestos implícitos sobre cómo debía ser y funcionar un partido político moderno, que era distinguido de las agrupaciones tradicionales por elementos como su mayor grado de organización formal y su carácter orgánicoprogramático. Luego, al analizar el discurso oficial de los principales dirigentes socialistas, en especial el contraste que establecían entre el PS y las fuerzas de la denominada "política criolla", noté cierta similitud entre las concepciones nativas y las académicas sobre los partidos políticos modernos. ${ }^{2}$ Entonces, me propuse analizar qué características eran las que ambas concepciones recuperaban. El presente artículo es un producto de dichas reflexiones.

El trabajo se encuentra dividido en tres apartados. En el primero, reconstruimos las principales características que según las concepciones nativas de los principales dirigentes del PS de comienzos de siglo XX debía tener un partido político para ser considerado moderno.

En el segundo, analizamos cómo se fueron conformando a lo largo del siglo XX las concepciones académicas sobre el PS como partido moderno. Para ello, rastreamos las características señaladas por obras extranjeras clásicas que abordaron los partidos políticos desde el aspecto organizacional y por las investigaciones sobre partidos en Argentina. También recuperamos las trayectorias políticas de algunas figuras clave del campo académico argentino para dar cuenta de sus vínculos con el socialismo. Nos interesa observar cómo se fue conformando entre los investigadores cierta idea sobre el PS que lo definió como el primer partido moderno, compartiendo elementos con las concepciones nativas, como el carácter orgánico-programático, la estructura organizativa, la disciplina militante y el centralismo partidario.

\footnotetext{
${ }^{1}$ Actualmente, la investigación forma parte de un proyecto de tesis doctoral financiado por una beca del CONICET, denominado "Expansión, estructuración e institucionalización del socialismo en el sudoeste bonaerense. El rol político-organizativo del Centro Socialista de Bahía Blanca, 1912-1937" y dirigido por la Dra. Silvina Jensen y co-dirigido por el Mg. Nicolás Quiroga.

2 Recuperando los aportes de la Antropología Social, entendemos por concepción nativa a la perspectiva de los agentes estudiados, con sus categorías y los sentidos que le asignan, en su contexto social, espacial y temporal específico. Por otra parte, concebimos por concepción académica a la perspectiva de los investigadores del campo académico, con sus marcos teóricoepistemológicos y sus categorías analíticas. Cfr. BALBI, Fernando y BOIVIN, Mauricio "La perspectiva etnográfica en los estudios sobre política, Estado y gobierno", en Cuadernos de Antropología Social, núm. 27, Buenos Aires, 2008, pp. 7-10.
} 
Por último, en el tercer apartado reflexionamos en torno a cómo los estudios sobre las prácticas políticas pueden ayudarnos a repensar la política desde sus formas concretas y no tanto desde visiones normativas sobre cómo debería funcionar la democracia en general y las organizaciones partidarias en particular. Asimismo, observamos cómo la variación de escala ha permitido poner en cuestión ideas instaladas en la historiografía sobre el socialismo argentino, tales como la disciplina y el centralismo partidario.

\section{Las concepciones nativas de los dirigentes socialistas argentinos sobre los partidos modernos}

En Argentina, hacia la década de 1890 los partidos comenzaron a ser aceptados por los intelectuales y políticos de la época como los legítimos organizadores del electorado y como los mediadores entre la sociedad civil y el Estado. Dicha legitimidad se fundaba más en un "deber ser" -basado en modelos externos de organicidad, permanencia y principios- que en prácticas concretas. Por ello, tanto radicales como conservadores se acusaban mutuamente de no constituir partidos, mientras que reconocían dichos atributos a los socialistas y a los demócrata-progresistas, a quienes sin embargo se les negaba carácter nacional. ${ }^{3}$

Aunque todos los actores políticos se hicieron eco de estos preceptos en el discurso público, el PS se presentó como el partido político moderno por antonomasia, buscando diferenciarse de las prácticas tradicionales de la "política criolla" que eran atribuidas al resto del arco político -prácticas tales como el faccionalismo, el personalismo y el clientelismo-.

La principal figura del socialismo argentino, Juan B. Justo, concebía al PS como una fuerza renovadora en el ámbito nacional, muy diferente de los partidos de la "política criolla", definidos como un "caos de facciones y camarillas", como agrupaciones efímeras, personalistas, sin programa ni principios, que hacían uso de mecanismos clientelares y de prácticas fraudulentas. En contraste con esta forma tradicional de hacer política, señalaba que las costumbres del PS eran "las de la democracia moderna", ya que tenía Centros organizados en los principales puntos del país y era la única agrupación política con actividad permanente que sostenía un programa, celebraba asambleas y votaba sus resoluciones. El PS era visto como el único partido orgánico, es decir como el único que representaba a alguna clase social

\footnotetext{
3 PERSELlO, Ana "Acerca de los partidos políticos, 1890-1943", en Anuario IEHS, núm. 15, Tandil, 2000, pp. 242 y 253-256. Los reformistas de 1912 también compartían esta idea de lo que debía ser un partido. De hecho, creían que la reforma electoral permitiría construir instituciones capaces de modificar las costumbres, dando lugar a un sistema de partidos competitivo e institucionalizado.
} 
moderna, por lo que era, según el líder socialista, "el único partido que existe" en Argentina. ${ }^{4}$

De acuerdo con Justo, entonces, los interlocutores de clase del socialismo no podían ser las fuerzas vinculadas al atraso político del país -como conservadores, radicales y anarquistas- sino que solo podrían llegar a serlo las clases propietarias, una vez que se modernizaran y conformaran un partido orgánico. Como señaló José Aricó, la concepción justista consideraba que esto era posible solo si ellas lograban

"constituir corrientes de opinión vertebradas en partidos políticos en el cabal y moderno sentido del término, es decir, instituciones en las que los intereses corporativos $\mathrm{y}$ particulares, y todos los personalismos que padecía el sistema político argentino, cedieran su lugar a los verdaderos intereses de clases, de los que tales partidos debían ser portavoces conscientes". 5

La concepción justista fue compartida por otras importantes figuras partidarias, incluso luego de la muerte de Justo. De hecho, a comienzos de la década de 1930 Nicolás Repetto continuaba señalando elementos similares para marcar la diferencia entre las "fuerzas tradicionales decadentes de la política argentina" y el PS, “el gran partido moderno y popular de la Argentina". ${ }^{6}$

La caracterización del PS como el partido político moderno por excelencia sería fomentada especialmente por la primera historia institucional del socialismo argentino. Según su autor Jacinto Oddone, el partido surgido luego del Congreso Constituyente de 1896 ya "era distinto a todos los demás; en su organización interna, en su método de lucha, en sus medios y en sus fines". ${ }^{7}$

Con respecto a la vida interna, Oddone argumentaba que el PS otorgaba iguales derechos y obligaciones a todos los afiliados, que era una institución regida por las "reglas más democráticas" y por "la mayor rigidez en la

${ }^{4}$ JUSTO, Juan Bautista "El profesor Ferri y el Partido Socialista Argentino", en Socialismo, La Vanguardia, Buenos Aires, 1920, pp. 129-141. La idea de organicidad remitía no solo al aspecto de su representación de una clase social moderna, sino también a que la organización funcionara en base a mecanismos democráticos que iban desde abajo hacia arriba (en el caso del PS, desde las resoluciones de las asambleas generales de los centros hasta las adoptadas por los congresos partidarios y por el voto general de los afiliados, pasando por las resoluciones de las federaciones provinciales y el Comité Ejecutivo). Ver también FALCÓN, Ricardo "Los socialistas y la cuestión nacional en Argentina. 1890-1900", en X Jornadas Interescuelas/Departamentos de Historia, Tucumán, 19 al 21 de septiembre de 2007, p. 8.

${ }^{5}$ ARICÓ, José La hipótesis de Justo. Escritos sobre el socialismo en América Latina, Sudamericana, Buenos Aires, 1999, p. 110.

${ }^{6}$ REPETTO, Nicolás Tiempos difíciles. Un compendio de socialismo aplicado, La Vanguardia, Buenos Aires, 1931, pp. 182-183.

7 ODDONE, Jacinto Historia del socialismo argentino, La Vanguardia, Buenos Aires, 1934, Tomo I, pp. 278-279. 
aplicación del estatuto", y que la conducta de la totalidad de sus miembros seguía la "más estricta disciplina". En cuanto al método de lucha, el PS "no sería un partido más, sino un partido mejor, armado de mejores recursos, en relación con sus propósitos"; en otras palabras, "una escuela de cultura y de civismo" donde la conferencia, el libro y el periódico serían los principales elementos para formar "hombres conscientes y capaces". Los medios de acción del PS no serían "los vulgares y corrientes de las facciones tradicionales; la promesa, el favor del jefe, la protección, la prebenda, la ayuda personal con fines de corrupción cívica y con miras a algún acto electoral", sino la organización sindical, la lucha comicial "sincera", la acción parlamentaria, y "la conquista del poder público sobre la base de la conciencia popular", entre otros. Por último, los fines del PS se resumían en el intento de transformar el sistema de producción capitalista, basado en la apropiación individual de las riquezas, por otro "basado sobre la distribución racional y equitativa de las mismas entre todos los miembros de la colectividad". La suma de estos elementos hacía del PS el "Partido político por excelencia, que aspiraba a transformar costumbres electorales, legislación, conceptos de administración y de gobierno, y a infundir en el país un verdadero espíritu republicano y democrático". ${ }^{\prime}$

En síntesis, varios de los principales dirigentes socialistas argentinos entendían que su partido era moderno porque era una institución orgánica que representaba intereses clasistas bajo el modo capitalista de producción, expresaba sus ideales de manera clara y definida en un programa partidario, funcionaba democráticamente, contaba con una estructura organizativa de alcance nacional sustentada por los mismos afiliados, y se preocupaba por la implementación de reformas políticas, económicas y sociales mediante mecanismos como la acción parlamentaria, la educación científica, la acción gremial y cooperativa.

Cabe señalar que esta postura no era exclusiva del socialismo argentino sino que formaba parte de la visión general del movimiento socialista, especialmente del europeo. De hecho, como señaló Geoff Eley, el partido político moderno -entendido como un modelo de organización política permanente, centralizada, coordinada programáticamente, y orientada a participar en elecciones, que estableció una continua presencia en la vida de sus sostenedores, los unió a través de complejos mecanismos de identificación y construyó duraderas culturas de solidaridad desde la vida cotidiana- fue inventado por los socialistas europeos en el último tercio del siglo XIX. En tal sentido, fue concebido como la forma organizacional distintiva de los socialistas, aun cuando luego de la Primera Guerra Mundial se convirtiera en la

8 ODDONE, Jacinto Historia del socialismo argentino, La Vanguardia, Buenos Aires, 1934, Tomo II, p. 256. 
forma de organización política predominante en Occidente, sea cual fuere su orientación política. ${ }^{9}$

\section{Las concepciones académicas sobre los partidos modernos}

Durante la primera mitad del siglo XX, distintas investigaciones enmarcadas en la Sociología Política, a partir de la preocupación por el pasaje de las sociedades tradicionales a las modernas, asignaron un papel relevante a la modernización de las prácticas llevada a cabo por los partidos políticos, especialmente por el PS.

Por un lado, en el caso de las organizaciones partidistas norteamericanas Moisei Ostrogorski destacó el papel modernizador de los "terceros partidos" entre ellos el socialista- frente a las prácticas corruptas de los partidos tradicionales..$^{10}$ Hacia mediados de siglo XX, Maurice Duverger opinaría en un sentido similar: al preguntarse por qué el sufragio universal y la entrada de las masas en la vida política no habían provocado el nacimiento de un partido de izquierda con estructura moderna, manifestaba que la inexistencia de un gran partido socialista en Estados Unidos y la "estructura arcaica" de los partidos en dicho país parecían deberse a la ausencia de conciencia de clase en el obrero norteamericano y a su individualismo profundo. ${ }^{11}$

Por otro lado, haciendo especial énfasis en el caso europeo, Max Weber distinguió entre las formas tradicionales de la dominación política y las modernas, considerando que los partidos solo alcanzan su tipo moderno en el estado legal con constitución representativa, mientras que su poder reside sobre todo en el grado de racionalidad organizativa de su burocracia. ${ }^{12}$ Por su parte, Duverger señaló que los partidos de creación electoral y parlamentaria correspondían a un tipo antiguo (de cuadros), que descansaba en comités relativamente independientes y descentralizados, en los que pequeños grupos de personalidades -adheridas por interés o costumbre más que por cuestiones doctrinarias o ideológicas- rivalizaban entre sí, orientando su acción totalmente hacia las elecciones. En cambio, los partidos de creación externa -surgidos de sindicatos, asociaciones, iglesias, grupos comerciales e industrialescorrespondían según el autor a un tipo moderno (de masas), caracterizado por

\footnotetext{
9 ELEY, Geoff Forging democracy. The History of the Left in Europe, 1850-2000, Oxford University Press, Nueva York, 2002, p. 24, 39, 113 y 501.

10 OSTROGORSKI, Moisei Democracy and the Organization of Political Parties, The Macmillan Company, London, 1902, Volume II, p. 456. Disponible en http://archive.org [ultimo acceso: 18/4/2016].

${ }^{11}$ DUVERGER, Maurice Los partidos politicos, Fondo de Cultura Económica, México, 1992, p. 52. [DUVERGER, Maurice Les partis politiques, Librairie Armand Colin, París, 1951].

12 WEBER, Max Economía y Sociedad. Esbozo de sociología comprensiva, Fondo de Cultura Económica, Madrid, 2002, p. 231 y 1080. [WEBER, Max Wirtschaft und Gesellschaft. Grundriss der Verstehender Soziologie, Mohr (Paul Siebeck), Tübingen, 1922].
} 
la naturaleza de su organización compleja y diferenciada, cuyos exponentes pioneros fueron los partidos socialistas de Europa continental, que constituyeron una organización de masas basada en una administración burocrática de cierta importancia y en un sistema de cotizaciones individuales que sostenían financieramente a la organización, permitiéndole no solo participar de la actividad electoral sino también educar políticamente a sus miembros en cuestiones doctrinarias. ${ }^{13}$

Estas obras devinieron en clásicos de la literatura sobre partidos políticos, abriendo líneas de investigación que fueron continuadas por trabajos posteriores. Como señaló recientemente Michel Offerlé, entre las principales tradiciones de análisis de los partidos políticos existieron ciertos obstáculos epistemológicos que dificultaron su comprensión. Entre ellos, cabe destacar el punto de vista normativo -que desde una mirada prescriptiva entendió a determinados partidos como "buenos" o "malos" (por ejemplo, en base a su contribución funcional al sistema democrático) - y el tipologista -que llevó a cabo una utilización rutinizada de los tipos ideales, con lo cual la clasificación tipológica devino un fin en sí mismo, confundiendo un instrumento analítico con la realidad empírica-. ${ }^{14}$ Así, la estructura organizativa racional-burocrática y centralizada y el carácter orgánico-programático del PS, fueron las características a partir de las cuales se lo interpretó como el modelo ideal del partido político "moderno", de masas.

En el caso del campo académico argentino, los trabajos de Gino Germani y José Luis Romero fueron clave en la consolidación de determinadas interpretaciones sobre la vida política argentina, en tanto dichos autores constituyeron figuras centrales del proceso de profesionalización de la Sociología y de la Historia respectivamente. A partir de una matriz de pensamiento socialista de carácter evolucionista, republicana y reformista, ambos interpretaron al fenómeno peronista como una manifestación vernácula del fascismo, y al PS como una de las principales instituciones que podrían colaborar con el mantenimiento del régimen democrático.

Dentro de las etapas de modernización económica, social y política señaladas por Germani, la sanción de la Ley Sáenz Peña habría abierto el período de la democracia representativa con participación ampliada, la cual

${ }^{13}$ DUVERGER, Maurice Los partidos..., cit., p. 11, 28 y 31-32. Como señaló Angelo Panebianco, Duverger dio cuenta de la consolidación del partido de masas en los regímenes democráticos, y "su misma obra puede ser leída, y lo ha sido, como un himno a las virtudes políticas del partido de masas", por lo que la consecuencia lógica del planteo del autor francés era considerar que los grandes partidos estadounidenses "constituían un caso manifiesto del «atraso» en el plano organizativo respecto a los partidos de masas del viejo continente". PANEBIANCO, Angelo Modelos de partido. Organización y poder en los partidos políticos, Alianza, México, 1993, p. 488. [PANEBIANCO, Angelo Modelli di partito, Il Mulino, Bologna, 1982].

${ }^{14}$ OFFERLÉ, Michel Los partidos políticos, LOM Ediciones, Santiago de Chile, 2004, pp. 15-24. 
estaría caracterizada por un aumento de la participación política "moderna" (que incluía al proletariado urbano) y por el surgimiento de los "partidos de masas modernos". ${ }^{15}$ Según el sociólogo italiano, el equilibrio político del país hacia 1930 se podría haber logrado mediante el fortalecimiento de un partido de izquierda democrática con apoyo popular, que asegurara el funcionamiento de una democracia representativa. ${ }^{16}$ Germani había participado en el movimiento antifascista durante la década de 1930 y recuperaba el diagnóstico del socialista liberal Carlo Rosselli, que consideraba que en momentos de crisis del liberalismo occidental en las sociedades de masas surgían tendencias totalitarias -como el régimen fascista y el soviético- que solo podían ser combatidas por un régimen socialista con plena vigencia de las libertades democráticas, por lo que creía que el PS podría haber contribuido a lograr el equilibrio político en Argentina. ${ }^{17}$

José Luis Romero, por su parte, tras estar vinculado hacia fines de la década de 1930 a una red de intelectuales que simpatizaban con el PS y publicar algunos artículos en La Vanguardia y en el periódico antifascista Argentina Libre, se afilió al partido en 1945. ${ }^{18}$ En un ensayo elaborado en dicho año, manifestó que el complejo social conformado hacia comienzos de siglo XX era "informe e inorgánico" pero "igualitario y democrático", y estaba compuesto por masas proletarias que depositaron sus ilusiones en un caudillo como Hipólito Yrigoyen y en el radicalismo (ideario "indefinido y reacio a toda sistematización"), en tanto que acogía "con frialdad al Partido Socialista cuando empezó a plantear con rigor los problemas sociales y políticos del proletariado". Esta lectura negativa del caudillismo y positiva del socialismo era retomada por el autor con respecto al peronismo, al que consideraba un fenómeno "amargo y peligroso" de demagogia y un peligro para la democracia, "mientras los partidos políticos populares de programa orgánico no aclaren su conciencia y no afronten la solución de sus problemas". ${ }^{19}$

En las últimas páginas de Las ideas políticas en Argentina -publicado en 1946-, este diagnóstico sería reiterado cuando Romero manifestaba que consideraba un deber de conciencia expresar su postura personal ante la

15 GERMANI, Gino Sociología de la modernización. Estudios teóricos, metodológicos y aplicados a América Latina, Paidós, Buenos Aires, 1969, p. 55.

16 GERMANI, Gino "La transición hacia un régimen político de participación total en la Argentina", en Política y sociedad en una época de transición. De la sociedad tradicional a la sociedad de masas, Paidós, Buenos Aires, 1974, p. 321.

17 RAWICZ, Daniela "Gino Germani: socialismo liberal y sociología científica", en Andamios. Revista de investigación social, Volumen 9, núm. 19, México, mayo-agosto 2012, pp. 237-244. Disponible en http://www.redalyc.org [último acceso: 18/4/2016].

${ }^{18}$ ACHA, Omar La trama profunda. Historia y vida en José Luis Romero, El Cielo por Asalto, Buenos Aires, 2005, pp. 35-62.

19 ROMERO, José Luis "El drama de la democracia argentina", en El drama de la democracia argentina, Centro Editor de América Latina, Buenos Aires, 1983, pp. 26-29. 
situación política, tras lo cual escribía: “Hombre de partido, el autor quiere [...] expresar sus propias convicciones, asentadas en un examen del que cree inferir que sólo la democracia socialista puede ofrecer una positiva solución a la disyuntiva entre demagogia y autocracia". ${ }^{20}$ Luego de que el peronismo triunfara en las elecciones de 1946, Romero expresó que los miembros de los partidos populares continuaban "seguros de la verdad de nuestros postulados y de la dignidad de nuestros fines", por lo que seguirían trabajando para lograr la adhesión de las masas populares. ${ }^{21}$

La participación de Romero en el PS se volvería más activa hacia fines de los años '50, cuando fue electo como miembro del Comité Ejecutivo (1957) y escribió en distintas publicaciones socialistas. En un artículo publicado en $\mathrm{La}$ Vanguardia el 31/1/1957, el autor expresaba que había llegado "La hora del socialismo" y que el partido debía esclarecer a la clase trabajadora mediante su sistema organizativo de cuadros militantes y un programa que fuera la expresión de la izquierda argentina. ${ }^{22}$ Sin embargo, en los años posteriores Romero se alejaría de la actividad partidaria debido a su elección como decano de la Facultad de Filosofía y Letras de la Universidad de Buenos Aires (19621966), mientras que en su producción académica iría disminuyendo la importancia asignada al socialismo en la resolución de las cuestiones abiertas por el populismo.

La concepción académica del PS argentino como organización partidaria moderna fue reforzada en la década de 1970, cuando el socialismo cobró mayor interés como objeto de estudio específico en nuestro país. Así, distintos investigadores norteamericanos definieron al PS como "el primer partido político argentino estructurado como tal", y como "uno de los primeros partidos políticos modernos de América Latina", señalando características como la clara definición estatutaria del funcionamiento organizacional y de los principios programáticos del partido, y diferenciándolo de otras agrupaciones políticas de la época que giraban en torno a un caudillo. ${ }^{23}$

Además, estos investigadores destacaron la existencia de otro elemento que también estaba presente en la visión nativa de los socialistas: la disciplina de los militantes. Ya Duverger había señalado hacia 1950 que en los partidos obreros las cuotas constituían el modo esencial de financiamiento partidario y garantizaban su independencia, por lo que los miembros "comprenden este

\footnotetext{
${ }^{20}$ ROMERO, José Luis Las ideas politicas en Argentina, Fondo de Cultura Económica, Buenos Aires, 1987, p. 297.

${ }^{21}$ ROMERO, José Luis "La lección de la hora", en La experiencia argentina y otros ensayos, Editorial de Belgrano, Buenos Aires, 1980, p. 446.

22 ROMERO, José Luis “La hora del socialismo", en El drama de la democracia..., cit., pp. 82-85.

${ }^{23}$ Respectivamente, ver SPALDING, Hobart La clase trabajadora argentina (Documentos para su historia - 1890/1912), Galerna, Buenos Aires, 1970, p. 65; y WALTER, Richard The Socialist Party of Argentina, 1890-1930, The University of Texas Press, Austin, 1977, p. xvii.
} 
carácter vital de la cuota y aceptan el sacrificio". ${ }^{24}$ Para el caso de la disciplina en el PS argentino, el énfasis no se puso tanto en el aspecto financiero sino en el de la conducta. Así, Hobart Spalding definió al PS como un "partido jerarquizado y disciplinado", que contaba hacia 1912 con una "reputación de rectitud al que no podían censurar ni sus peores enemigos", 25 mientras que Richard Walter señaló que las medidas disciplinarias suponían la adherencia a una exigente norma de conducta pública y privada. ${ }^{26} \mathrm{El}$ caso paradigmático que se señaló como ejemplo de la disciplina socialista fue la expulsión de Alfredo Palacios en 1915 por batirse a duelo, conducta que estaba expresamente prohibida por los estatutos pero que hasta entonces no había sido aplicada a ningún legislador socialista. ${ }^{27}$

En la década de 1980, tras la finalización del autodenominado "Proceso de Reorganización Nacional" (1976-1983) y la realización de elecciones que dieron paso a la presidencia de Raúl Alfonsín (1983-1989), un importante grupo de cientistas sociales centró su interés en el análisis de la cultura política argentina, reavivando los estudios sobre la trayectoria del PS -que los autores de la izquierda revolucionaria y del revisionismo populista habían caracterizado como elitista, antipopular y cipayo- y revalorizando su papel como formador de una cultura ciudadana y democrática. ${ }^{28}$

Una hipótesis que reflejó claramente los intereses propios de esta coyuntura fue la de los académicos nucleados en torno al Programa de Estudios de Historia Económica y Social Americana (PEHESA), quienes señalaron la histórica capacidad de los sectores populares para generar y alimentar procesos de participación igualitaria en organizaciones celulares -como gremios, sociedades de socorros mutuos, sociedades de fomento, clubes, bibliotecas populares y agrupaciones partidarias de base (especialmente, los centros socialistas)- que actuarían como "nidos" de la democracia, en los cuales esta se

${ }^{24}$ DUVERGER, Maurice Los partidos..., cit., p. 103. En cambio, los partidos de cuadros no requerían afiliados disciplinados porque se financiaban con la fortuna de sus dirigentes.

${ }^{25}$ SPALDING, Hobart La clase trabajadora argentina..., cit., p. 59 y 76.

${ }^{26}$ WALTER, Richard The Socialist Party..., cit., p. 27.

${ }^{27}$ Como señaló Martínez Mazzola, los estatutos del PS prohibían los duelos en un intento por subrayar la distancia entre los socialistas y los representantes de la política criolla que en nombre del honor caballeresco llevaban a cabo una práctica como los duelos, considerada por los socialistas como una costumbre inmoral y negativa para la educación política del pueblo. MARTÍNEZ MAZZOLA, Ricardo El Partido Socialista y sus interpretaciones del radicalismo argentino (1890-1930) (Tesis de Doctorado en Historia), Universidad Nacional de Buenos Aires, Buenos Aires, 2008, pp. 248-249.

28 Para una reconstrucción de la historiografía política argentina en este período, ver SPINELLI, María Estela "Historiografía política argentina. Explicación y comprensión en el análisis de la segunda mitad del siglo XX", en Anuario del Centro de Estudios Históricos Prof. Carlos S. A. Segreti, núm. 7, Córdoba, 2007, pp. 311-327. Disponible en http://www.cehsegreti.org.ar [último acceso: 18/4/2016]. 
refugia y mantiene latente cuando el sistema político se vuelve restrictivo. ${ }^{29}$ Según la interpretación de Luis Alberto Romero, uno de los miembros más destacados dentro del PEHESA, las prácticas llevadas a cabo por el peronismo, caracterizadas por el autor como verticalistas y autoritarias, eran incompatibles con aquellos embriones de participación, por lo que "se interrumpió totalmente la tradición anterior", anteponiendo la "legitimación plebiscitaria" a otras dimensiones de la democracia tales como la discusión, el pluralismo y la elaboración de abajo hacia arriba. ${ }^{30}$

Así, se instaló un relato de tipo "histórico-filosófico socialista que postula un país integrado y democrático", ${ }^{31}$ y se cristalizó una interpretación dicotómica de las formas de hacer política en Argentina que establecía una diferencia entre una forma cívica o moderna, y una facciosa o tradicional, la primera en general asociada al socialismo y la segunda al radicalismo, conservadurismo y peronismo. ${ }^{32}$

La recuperación del pasado socialista argentino no solo fue llevada a cabo por los investigadores del PEHESA. Desde el exilio en México, intelectuales socialistas abrieron el camino a dicha revalorización reflexionando desde la revista Controversia (1979-1981) y desde el Grupo de Discusión Socialista, en torno a las dificultades encontradas por las experiencias partidarias para convertir al socialismo en una opción de masas en Argentina. Entre los aportes de este grupo de intelectuales nos interesa mencionar los de Juan Carlos Portantiero y los de José María Aricó.

Por un lado, Portantiero, luego de señalar la falta de comprensión del carácter nacional-popular del peronismo por parte de la izquierda tradicional -

\footnotetext{
29 PEHESA “¿Dónde anida la democracia?”, en Punto de Vista, núm. 15, Buenos Aires, agostooctubre 1982, p. 6. El PEHESA estaba integrado entonces por Ricardo González, Leandro Gutiérrez, Hilda Sábato, Juan Carlos Korol, Luis Alberto Romero y Miriam Trumper. Años más tarde, Gutiérrez y Romero ahondaron en la hipótesis de los nidos de democracia interpretándolos como parte del proceso de constitución de la identidad conformista y reformista en los sectores populares porteños durante el período de entreguerras. GUTIÉRREZ, Leandro y ROMERO, Luis Alberto Sectores populares, cultura y política. Buenos Aires en la entreguerra, Sudamericana, Buenos Aires, 1995, pp. 11-13. Por su parte, Sábato analizó las prácticas de participación política y de intervención pública de los porteños entre 1862 y 1880, señalando que su obra estuvo marcada por "la hipótesis, tal vez demasiado optimista, de la histórica capacidad de nuestros sectores populares para generar celulares "nidos de democracia" en el seno de la sociedad civil". SÁBATO, Hilda La política en las calles: entre el voto y la movilización, Buenos Aires, 1862-1880, Universidad Nacional de Quilmes, Bernal, 2004, p. 29. 30 ROMERO, Luis Alberto "Participación política y democracia, 1880-1984", en GUTIÉRREZ, Leandro y ROMERO, Luis Alberto Sectores populares..., cit., pp. 130-131.

${ }^{31}$ ACHA, Omar Historia crítica de la historiografía argentina: las izquierdas en el siglo XX, Prometeo, Buenos Aires, 2009, pp. 63-64.

${ }^{2}$ GENÉ, Mariana y VOMMARO, Gabriel "Presentación. Por una sociología de lo político", en OFFERLÉ, Michel Perímetros de lo político: contribuciones a una socio-historia de la política, Antropofagia, Buenos Aires, 2011, p. 20.
} 
que desmereció su importancia en la constitución de los obreros como clase-, cuestionó la manera en que desde la izquierda se había pensado la relación entre socialismo y democracia, y destacó la relevancia de la práctica democrática para la constitución política de las clases. También sostuvo que la eficacia de las extensas redes de socialización de los socialistas se había visto limitada por su concepción pedagógica de la política, que al despreciar los resortes emocionales de la comunicación terminó planteando un discurso elitista. ${ }^{33}$ Por otro lado, Aricó observó, en una línea similar, que la incapacidad del movimiento obrero para superar la defensa de sus intereses corporativos le había impedido funcionar como polo de agregación del mundo popular subalterno y plantear una estrategia de transformación social. ${ }^{34}$

Luego de que Portantiero y Aricó regresaran a Argentina, los intelectuales de izquierda que integraban el Grupo de Discusión Socialista y la revista Punto de Vista se unieron para fundar el Club de Cultura Socialista en 1984. ${ }^{35}$ En su Declaración de Principios destacaron su deseo por consolidar la democracia y favorecer el desarrollo de una corriente socialista y democrática, abandonando así la preeminencia otorgada previamente a los métodos y concepciones radicales para la consecución de objetivos políticos. La apuesta discursiva del presidente Alfonsín por una concepción amplia y plural de la democracia, como corte simbólico y material con un pasado autoritario, encontró puntos de contacto con la transformación que varios miembros del Club venían proponiendo desde 1978. Así, distintos integrantes del Club no solo apoyaron las medidas iniciales de Alfonsín, ${ }^{36}$ sino que algunos de ellos, como Portantiero y De Ipola, integraron el Grupo Esmeralda, comité asesor del entonces presidente. ${ }^{37}$

\footnotetext{
33 Años más tarde, Portantiero volvería sobre estas cuestiones al plantear que la "concepción racionalista de la política" llevó a los dirigentes socialistas a menospreciar a las demás agrupaciones -por inorgánicas, personalistas, clientelistas, aprogramáticas-. PORTANTIERO, Juan Carlos Juan B. Justo: un fundador de la Argentina moderna, Fondo de Cultura Económica, Buenos Aires, 1999, p. 49. Como señalaría luego Martínez Mazzola, la concepción justista y el principismo socialista colocaron al PS en una posición de orgulloso apartamiento al menos hasta la década de 1930, lo cual se tradujo en una ausencia de alianzas con las demás fuerzas políticas. MARTÍNEZ MAZZOLA, Ricardo El Partido Socialista..., cit., 619.

${ }^{34}$ MARTÍNEZ MAZZOLA, Ricardo "Un difícil encuentro. Portantiero y la tradición socialista argentina", en HILB, Claudia (comp.) El político y el científico: ensayos en homenaje a Juan Carlos Portantiero, Siglo XXI, Buenos Aires, 2009, pp. 142-151.

35 Entre las figuras más destacadas de Punto de Vista pueden mencionarse Beatriz Sarlo, Carlos Altamirano, Hugo Vezzetti y Adrián Gorelik, mientras que el grupo proveniente del exilio en México tenía entre sus miembros más notables a Aricó, Portantiero, Jorge Tula y Emilio De Ipola.

36 Aricó destacó en el $\mathrm{N}^{\circ} 1$ de La Ciudad Futura (1986) que no eran ni radicales ni socialdemócratas, sino socialistas que compartían convicciones con el gobierno de Alfonsín.

${ }_{37}$ PONZA, Pablo "El Club de Cultura Socialista y la gestión Alfonsín: transición a una nueva cultura política plural y democrática", en Nuevo Mundo Nuevos Mundos, Questions du temps
} 
En este contexto, se recuperó la figura de Juan B. Justo como impulsor de una propuesta original de articulación entre la Segunda Internacional y un país latinoamericano, y como promotor de reformas desde abajo. ${ }^{38}$ En cuanto a las consideraciones en torno al PS, tanto en Aricó como en Portantiero podemos encontrar similitudes con los planteos previos que postulaban al PS como el partido moderno de la Argentina, enfatizando los aspectos organizativos y los orgánico-programáticos. Según Aricó, la fundación del PS "no sólo significó el surgimiento de la primera organización política del proletariado, sino también el punto de arranque del proceso de formación de los modernos partidos políticos en Argentina". ${ }^{39}$ Por su parte, Portantiero manifestó que la forma de organización partidaria del PS se distanciaba de la de conservadores y radicales en varios aspectos: la actividad de los centros (a diferencia de la de los comités); la estructura de la militancia que dependía de las cotizaciones (a diferencia de las agrupaciones que dependían del caudillo) y los modos de funcionamiento orgánico (desde la base hasta la cúpula de la organización) mediante el cumplimiento estricto de fórmulas estatutarias, lo que convirtió al PS "en el primer partido moderno de la Argentina" y en "un partido popular poderoso, ideológicamente firme y centralizadamente organizado. [...] un partido de ideas". ${ }^{40}$

Sin negar la excelente calidad académica de los trabajos de esta generación de investigadores, nos interesa destacar que si bien efectivamente el PS introdujo en el sistema político argentino la novedad de un partido político orgánico, programático, organizado y permanente, entre los analistas del socialismo argentino se consolidó en este clima epocal cierta imagen que enfatizó los elementos formales-institucionales valorándolos positivamente, ya que como señaló María Liliana Da Orden, el PS fue concebido como la institución partidaria moderna que, en virtud de sus peculiares prácticas políticas y socio-culturales reformistas, sustentadas en la razón, en una sólida estructura burocrática y en un perfil partidario orgánico y programático, habría colaborado en la transformación de la vida política tradicional, marcada por las prácticas facciosas y clientelares impulsadas por grupos personalistas e inorgánicos. ${ }^{41}$

Además, la concepción académica del PS como partido moderno incorporó ciertos supuestos cuya contrastación empírica ha sido escasa, en

présent, en línea desde el 15 de febrero de 2013. Disponible en https://nuevomundo.revues.org/ [último acceso: 18/4/2016].

${ }^{38}$ MARTÍNEZ MAZZOLA, Ricardo “Un difícil encuentro. Portantiero...", cit., pp. 151-153.

${ }^{39}$ ARICÓ, José La hipótesis..., cit., pp. 126-127.

${ }^{40}$ PORTANTIERO, Juan Carlos Juan B. Justo..., cit., p. 10 y 44.

${ }^{41}$ DA ORDEN, María Liliana "¿Prácticas tradicionales en un partido moderno? Socialismo y poder local, Mar del Plata 1916-1929", en DEVOTO, Fernando y FERRARI, Marcela (comps.) La construcción de las democracias rioplatenses: proyectos institucionales y prácticas políticas, 1900-1930, Biblos, Buenos Aires, 1994, p. 229. 
especial el de la extensión de una férrea disciplina por parte de los afiliados y el de una organización que en la práctica funcionaba de manera centralista.

En cuanto a la consolidación y reproducción de cierta imagen de la disciplina socialista, un trabajo clave fue el de Sergio Berensztein. Si bien tuvo menor difusión que los textos vinculados con los "nidos de la democracia", constituyó una de las primeras y escasas investigaciones específicas sobre el funcionamiento interno del PS argentino. Según el autor, los estatutos partidarios "fueron firmemente respetados" por los socialistas, quienes "tenían tal grado de identificación con esas normas" que se comportaron como "celosos defensores" de las mismas, convirtiéndolas en "una regla de juego esencial en la vida partidaria". ${ }^{42}$ Esta interpretación, que partía de las declamaciones de los principales dirigentes partidarios sobre la disciplina y de su accionar en determinadas circunstancias (como por ejemplo la expulsión de Alfredo Palacios por batirse a duelo), fue generalizada al conjunto de las prácticas cotidianas de los afiliados de base, las cuales no fueron analizadas, probablemente debido a la escasez de fuentes documentales directas. ${ }^{43}$

Otros trabajos como el de Aníbal Viguera, menos vinculados a la historia partidaria, se hicieron eco de la idea sobre los socialistas como respetuosos rigurosos de las normas disciplinarias, señalando "que todas las fuentes coinciden siempre en señalar el 'orden' y la 'cultura' de las marchas socialistas" del 1 de mayo en la primera mitad del siglo XX. ${ }^{44}$ Cabe señalar que este texto, como la gran mayoría de las útiles investigaciones sobre socialismo circulantes en el mundo académico, se basa sobre todo en fuentes periodísticas y en el accionar público de los principales dirigentes socialistas, las cuales en general presentan al partido desde la postura oficial y en la esfera pública. Las dificultades para complementar estos bien documentados trabajos con la consulta de fuentes directas sobre la vida partidaria -dificultades que guardan relación con la falta de una política de archivo sistemática en Argentina, unida a la destrucción intencional de documentación de organizaciones, bibliotecas y militantes de izquierda- ${ }^{45}$ ha obstaculizado el conocimiento de la actividad de los militantes al interior de los centros.

42 BERENSZTEIN, Sergio Un partido para la Argentina moderna. Organización e identidad del Partido Socialista (1896-1916), CEDES, Buenos Aires, 1991, pp. 14-18.

${ }^{43}$ La visión oficial sobre la disciplina fue cuestionada por Aricó, quien señaló que los dirigentes socialistas, al privilegiar la dimensión formal-institucional en la percepción del movimiento de las clases subalternas, exageraban la rigidez organizativa y política de sus instituciones y el puritanismo moral de sus militantes. ARICÓ, José La hipótesis..., cit., p. 116.

${ }^{44}$ VIGUERA, Aníbal "El primero de mayo en Buenos Aires, 1890-1950. Evolución y usos de una tradición", en Boletín del Instituto de Historia Argentina y Americana "Dr. E. Ravignani", núm. 3, Buenos Aires, primer semestre 1991, p. 64.

45 TARCUS, Horacio "Los archivos del movimiento obrero, los movimientos sociales y las izquierdas en la Argentina. Un caso de subdesarrollo cultural", en Políticas de la Memoria, núm. 10/11/12, Buenos Aires, verano 2011/12, pp. 7-18. 
El otro elemento que fue asociado a la imagen moderna del PS fue el centralismo del partido. Investigaciones interesadas por los aspectos organizacionales señalaron que el Comité Ejecutivo (CE) se convirtió en la unidad administrativa más poderosa de la estructura organizacional, ya que tenía a su cargo tareas como organizar el funcionamiento de congresos y/o votos generales e instrumentar sus decisiones, administrar los fondos, dirigir la propaganda, garantizar el respeto de los afiliados a los estatutos y al programa, y establecer relaciones con partidos y organizaciones afines en otros países. ${ }^{46}$ Así, se afirmó que las atribuciones ejecutivas concentradas por el CE "implicaban en la práctica un manejo discrecional de los asuntos partidarios". ${ }^{47}$

Estas investigaciones hicieron hincapié en que, más allá de que el CE fuera el órgano que concentraba mayor poder, la estructura federalizada del partido respetaba las autonomías locales. En cambio, en un artículo publicado en una colección de importante difusión como fue la Nueva Historia Argentina, se afirmó que el PS

"prefería una estrecha centralización a cargo del Comité Ejecutivo. Los locales regionales eran fundados por delegados de la Capital y las credenciales de estas sucursales debían ser aprobadas por la dirigencia central. Esto dejaba poco espacio para la organización espontánea desde abajo o para plantear programas partidarios regionales que tuvieran en cuenta los temas o intereses locales específicos" ${ }^{48}$

Así, las interpretaciones sobre la centralización del PS transitaron dos vías. Por un lado, una que planteó que la estructura organizativa del partido favorecía las tendencias centralistas, pero que evitó afirmar que la institución funcionara de manera verticalista. ${ }^{49}$ Por otro, una que propuso que no solo la estructura sino el funcionamiento efectivo del partido era centralizado, por lo que los centros del interior quedaban "subordinados y dependientes de la conducción política centralizada en la Capital". ${ }^{50}$

En las últimas décadas del siglo XX se dio un importante desarrollo de la investigación académica sobre la izquierda argentina en general y sobre el socialismo en particular. Además de profundizarse el análisis de temáticas ya

\footnotetext{
${ }^{46}$ WALTER, Richard The Socialist Party..., cit., p. 26.

${ }^{47}$ BERENSZTEIN, Sergio Un partido para la Argentina..., cit., p. 15.

48 ADELMAN, Jeremy "El Partido Socialista Argentino", en LOBATO, Mirta (dir.) Nueva Historia Argentina. El progreso, la modernización y sus límites (1880-1916), Sudamericana, Buenos Aires, 2000, Tomo V, pp. 283-284.

49 BARRANCOS, Dora Educación, cultura y trabajadores (1890-1930), Centro Editor de América Latina, Buenos Aires, p. 95; PORTANTIERO, Juan Carlos Juan B. Justo..., cit., p. 44.

${ }^{50}$ SCHERLIS, Gerardo "La reforma política de 1912, federalismo y sistema de partidos. El caso del Partido Socialista", en VI Congreso Nacional de Ciencia Política, Rosario, 5 al 8 de noviembre de 2003, p. 25.
} 
abordadas por trabajos previos -tales como la historia institucional, la trayectoria y las ideas de las principales figuras partidarias, la actuación parlamentaria del partido, sus vínculos con el movimiento obrero-, se prestó atención a otras cuestiones, tales como la conflictiva dinámica interna del PS, sus formas de intervención en la escena pública y sus iniciativas culturales y educativas. ${ }^{51}$

Este desarrollo de las investigaciones sobre el socialismo argentino comenzó a dialogar recientemente con los estudios sobre las prácticas políticas a comienzos de siglo $\mathrm{XX}$, los cuales pretendieron tomar distancia de visiones prescriptivas implícitas y de ideas instaladas en la literatura a través del análisis de la política desde sus formas concretas. Esto permitió reformular la concepción académica sobre los partidos políticos -escapando a la dicotomía tradicional/moderno- y poner en cuestión imágenes arraigadas en la historiografía sobre el PS, tales como la disciplina y el centralismo partidario. En la siguiente sección analizamos los aportes de esa línea de investigación.

\section{Los estudios sobre las prácticas políticas de comienzos de siglo XX}

En el último cuarto del siglo $X X$ se desarrolló con fuerza la Nueva Historia, que se interesó por el estudio de toda la gama de actividades humanas a través de una multiplicidad de fuentes, desde una perspectiva procesual, relativista y constructivista que contribuyó a la interdisciplinariedad..$^{52}$

Esta renovación de objetos, fuentes y perspectivas encontró su traducción entre los historiadores interesados por lo político en el libro Pour une histoire politique.53 Dicha obra colectiva fue considerada como uno de los textos fundantes de la Nueva Historia Política, la cual fue caracterizada por su mayor interés por lo político antes que por la política, partiendo de un concepto pluridisciplinario de poder, que conserva su especificidad pero es vinculado a factores económicos, sociales, culturales y simbólicos. ${ }^{54}$ En el caso del análisis de la política argentina, esta renovación se tradujo en el interés por temáticas como las formas de soberanía, representación y participación, los lenguajes políticos e identidades colectivas, y la esfera pública y sus instituciones, en el marco de

\footnotetext{
${ }^{51}$ Para un estado de la cuestión al respecto, remitimos a CAMARERO, Hernán y HERRERA, Carlos "El Partido Socialista en Argentina: nudos históricos y perspectivas historiográficas", en El Partido Socialista en Argentina. Sociedad, política e ideas a través de un siglo, Prometeo, Buenos Aires, 2005, pp. 9-73.

52 BURKE, Peter "Obertura: la nueva historia, su pasado y su futuro", en Formas de hacer historia, Alianza, Madrid, 1996, pp. 13-16. [BURKE, Peter New Perspectives on Historical Writing, Polity Press, Cambridge, 1991].

${ }^{53}$ RÉMOND, René Pour une histoire politique, Le Seuil, París, 1988.

${ }^{54}$ LE GOFF, Jacques "Los retornos en la historiografía francesa actual”, en Prohistoria, núm. 1, Rosario, 1997, p. 36.
} 
una reformulación de los interrogantes sobre las dirigencias, organizaciones y mecanismos para alcanzar y conservar el poder..$^{55}$

Uno de los tópicos que recibió mayor atención entre los hacedores de la Nueva Historia Política en Argentina fue el análisis de las formas de hacer política a comienzos de siglo XX. ${ }^{56}$ Entre las temáticas abordadas pueden mencionarse el caudillismo, el clientelismo y el personalismo, presentes sobre todo en los estudios sobre radicales y conservadores. Así, investigaciones que dieron cuenta de la interrelación entre caudillos y partidos políticos, ${ }^{57}$ y que recuperaron el papel clave que lo relacional desempeña en los distintos espacios de la vida pública -considerando que la utilización de vínculos personales está en la base del hacer político, más allá de que se encuentren en sociedades definidas como tradicionales $\mathrm{o}$ modernas $-{ }^{58}$ permitieron matizar la interpretación dicotómica que oponía las prácticas tradicionales (facciosas, clientelares, personalistas, inorgánicas) a las modernas (partidarias, racionales y burocráticas, impersonales, orgánicas e ideológico-programáticas). ${ }^{59}$

Este tipo de planteos se desarrollaron también en otras Ciencias Sociales. Por ejemplo, el análisis sociológico de las prácticas políticas peronistas en clave relacional permitió objetar los presupuestos según los cuales el clientelismo

55 SÁBATO, Hilda "La política argentina en el siglo XIX: notas sobre una historia renovada", en PALACIOS, Guillermo (coord.) Ensayos sobre la nueva historia política de América Latina, siglo XIX, El Colegio de México, México, 2007.

56 Junto con las prácticas políticas, otro objeto que comenzó a ser analizado sistemáticamente, abriendo una promisoria línea de investigación, fue el de los costos de la política, especialmente en MAURO, Diego y LICHTMAJER, Leandro (comps.) Los costos de la política. Del centenario al primer peronismo, Imago Mundi, Buenos Aires, 2014.

57 BALMORI, Diana; VOSS, Stuart y WORTMAN, Miles Notable Family Networks in Latin America, Chicago University Press, Chicago, 1984.

${ }^{58}$ DA ORDEN, María Liliana “¿Prácticas tradicionales...", cit., p. 241.

59 Para el caso del siglo XIX, un estudio sobre las formas de hacer política que tomó en consideración lo tradicional y lo moderno ha sido: GAYOL, Sandra Honor y duelo en la Argentina moderna, Siglo XXI, Buenos Aires, 2008. La autora sometió a revisión la idea de que el duelo de honor era un privilegio aristocrático y una rémora del pasado destinada a desaparecer con la irrupción de la modernidad, y destacó que fueron precisamente los cambios acaecidos en la Argentina a partir de 1880 (crecimiento económico y poblacional, cambios en la estructura social y trastocamiento de las jerarquías) los que favorecieron la permanencia de dicha práctica, que desempeñó un papel crucial como mecanismo de distinción, vinculando a los miembros de las élites y funcionando como un símbolo de pertenencia que los diferenciaba del resto de los hombres. Un sistema político argentino como el de fines de siglo XIX, en el que las lealtades personales y los liderazgos fuertes mantenían su primacía, facilitó la extensión de un habitus que consideraba al duelo como una forma moderna de solucionar un conflicto de honor y mostrar valor y capacidad para mandar. Moderna en el sentido de civilizada y pacífica, ya que el código de honor pautaba reglas de comportamiento y rituales que permitían regular las pasiones y mesurar la violencia, convirtiendo al duelo en un tipo de violencia estilizada y formalizada, legítima y legitimante, distinta de otras formas violentas de dirimir diferencias y defender el honor, como el duelo popular. En tal sentido, honor y duelo fueron vitales en el proceso de construcción de lo político en la modernidad argentina. 
representaría una forma de hacer política tradicional, atrasada y perjudicial para la democracia en tanto representaría actos de manipulación y/o de intercambio material. En cambio, se señaló que el acto de intercambio es tan solo un evento puntual que se asienta en una serie de redes informales y de representaciones culturales compartidas que se constituyeron previamente. De esta manera, estas investigaciones señalaron que modelos normativos -como la antinomia entre política tradicional-clientelística y formas de participación moderna- pueden transformarse en importantes obstáculos epistemológicos en nuestra comprensión del funcionamiento de la democracia, sobre todo porque dichos modelos rara vez se someten a investigación empírica, por lo que se convierten más bien en una simplificación que una herramienta analítica útil. ${ }^{60}$

Estos cambios en las formas de concebir las prácticas políticas permitieron repensar la Reforma electoral de 1912 y la idea misma de partido político moderno. Así, el impacto efectivo de la Ley Sáenz Peña fue matizado, si bien no dejó de ser concebida como un hito en la historia argentina, que produjo cambios en la importancia que los partidos debían dar a la diagramación de las estrategias de campaña electoral, tales como giras de propaganda, alquiler de locales, realización de folletos y carteles, entre otros. ${ }^{61}$ A diferencia de interpretaciones previas que la entendían en un sentido rupturista, es decir como un signo de modernización política que habría significado un quiebre en la política nacional, distintos investigadores adoptaron un enfoque que recupera elementos de continuidad tanto en el ámbito de las ideas como en el de las prácticas, como la persistencia de modalidades clientelares y prácticas fraudulentas en el ejercicio político. ${ }^{62}$

Por otra parte, el reconocimiento del importante esfuerzo que tanto el Partido Conservador bonaerense como la Unión Cívica Radical hicieron para

\footnotetext{
${ }^{60}$ AUYERO, Javier La política de los pobres. Las prácticas clientelistas del peronismo, Manantial, Buenos Aires, 2001, pp. 35-37.

${ }^{61}$ CASTRO, Martín "Partidos políticos, opinión pública y estrategias de comunicación en los períodos pre-electorales. La provincia de Buenos Aires, 1912-1941", en SPINELLI, María; SERVETTO, Alicia y FERRARI, Marcela (comps.) La conformación de las identidades políticas en la Argentina del siglo XX, Ferreyra Editor, Córdoba, 2000, pp. 125-156.

${ }^{62}$ Entre otros, SÁBATO, Hilda "La Revolución del 90: ¿prólogo o epílogo?", en Punto de Vista, núm. 39, Buenos Aires, diciembre de 1990, pp. 27-31; DEVOTO, Fernando, FERRARI, Marcela y MELÓN, Julio "The Peaceful Transformation? Changes and Continuities in Argentinian Political Practices, 1910-1922", en DEVOTO, Fernando y DI TELLA, Torcuato (eds.) Political Culture, Social Movements and Democratric Transitions in South America in the XXth Century. Annali, Feltrinelli, Milán, pp. 167-192; PERSELLO, Ana y DE PRIVITELLIO, Luciano "Las reformas de la Reforma: la cuestión electoral entre 1912 y 1945", en 2das Jornadas sobre la política en Buenos Aires en el siglo XX, Tandil, 28 y 29 de junio de 2007. Disponible en http://historiapolitica.com [último acceso: 18/4/2016]; BERTONI, Lilia y DE PRIVITELLIO, Luciano (comps.) Conflictos en democracia: la vida política argentina entre dos siglos, 1852-1943, Siglo XXI, Buenos Aires, 2009.
} 
adaptarse a la situación política posterior a la reforma de $1912,{ }^{63}$ abrió el camino a la reformulación de la concepción académica de partido moderno, de manera de incluir a estas fuerzas políticas que en general habían quedado excluidas de dicha definición por sus prácticas consideradas tradicionales. Así, se retomaron los planteos de Hobsbawm para las agrupaciones europeas de fines del XIX, quien señaló que antes que el programa concreto -históricamente cambiante- lo que distinguía a los partidos modernos era el hecho de que eran "ideológicos" en tanto representaban una visión del mundo, y "globales" en tanto quebraron el marco local o regional de la política. ${ }^{64} \mathrm{~A}$ partir de esta definición, tanto el radicalismo argentino como el Partido Conservador bonaerense fueron considerados por algunos académicos, en contraste con las concepciones nativas, como partidos políticos modernos. ${ }^{65}$

Entonces, al definir a los partidos como las organizaciones que se enfrentaban en un sistema de partidos competitivos, representando una visión del mundo y quebrando el marco local o regional de la política, los analistas de la política argentina establecieron cierto consenso que les permitió superar las tensiones interpretativas derivadas de la oposición entre lo tradicional (faccionalismo, clientelismo, personalismo) y lo moderno (formas cívicas de hacer política).

Si bien este consenso se alcanzó para los estudios sobre el radicalismo y el conservadurismo de comienzos de siglo XX, el PS permaneció hasta hace poco prácticamente indemne frente a las discusiones en torno a las formas de hacer política. De hecho, como señalaron los autores de una de las compilaciones más recientes y actualizadas sobre el socialismo argentino, "el PS viene siendo entendido como un 'partido moderno' en la Argentina de

\footnotetext{
${ }^{63}$ En el caso de los conservadores, un claro ejemplo fue la reforma de la Ley Electoral provincial (1913), que estableció el voto secreto y obligatorio, así como ciertos mecanismos de reaseguro para controlar instancias claves previas al comicio, como la construcción y depuración del registro electoral. MELÓN, Julio “La Ley Sáenz Peña de Ugarte, o el éxito de la reforma conservadora en la provincia de Buenos Aires", en DEVOTO, Fernando y FERRARI, Marcela (comps.) La construcción de las democracias rioplatenses..., cit., p. 123. Por su parte, la Unión Cívica Radical, aunque fuera un partido descentralizado, fragmentado y escasamente institucionalizado, se presentaba como un partido orgánico, impersonal y de principios, y no se diferenció sustancialmente de los partidos europeos y estadounidenses que se desarrollaron con la democracia de masas. PERSELLO, Ana El partido radical: gobierno y oposición, 1916-1943, Siglo XXI, Buenos Aires, 2004, p. 14 y 53.

64 HOBSBAWM, Eric La era del imperio: 1875-1914, Crítica, Buenos Aires, 2007, p. 103. [HOBSBAWM, Eric The age of empire. 1875-1914, Weidenfeld and Nicolson, London, 1987]. 65 PERSELLO, Ana El partido radical..., cit., p. 13; BISSO, Matías “El Partido Conservador de la Provincia de Buenos Aires ¿el fraude de masas?", en BOHOSLAVSKY, Ernesto y ECHEVERRÍA, Olga (comps.) Las derechas en el Cono Sur, siglo XX. Actas del tercer taller de discusión, Universidad Nacional de General Sarmiento, Los Polvorines, 2013. Disponible en http://www.ungs.edu.ar/derechas/ [último acceso: 18/4/2015].
} 
comienzos del siglo XX, según una caracterización en boga en el campo historiográfico" ${ }^{\prime 66}$

Esta definición de partido moderno, que pone el énfasis en los aspectos organizativos, orgánicos y programáticos como base de la definición del partido como tal, se apoya en el supuesto teórico y normativo generalmente implícito sobre lo que debería ser un "verdadero" partido, supuesto que lo concibe sobre todo como una organización, por lo que mide su fortaleza o debilidad en base al grado de desarrollo formal e institucional. ${ }^{67}$ Esto no hace más que entramparnos en la dicotomía entre formas tradicionales y cívicas de hacer política.

En los últimos años ha crecido el estudio de las formas concretas de la política socialista en Argentina, abriendo una prometedora línea de investigación que permite eludir visiones prescriptivas implícitas sobre cómo debería ser el comportamiento político de las personas o el funcionamiento de los partidos políticos. ${ }^{68}$ Ello ha sido posible en buena parte gracias a la utilización de la perspectiva microanalítica, enfoque constructivista que plantea la reducción de escala como una operación que realiza el investigador para dar forma a su objeto de investigación. ${ }^{69}$ Este cambio de foco a lo local procura evitar los relatos localistas -con su énfasis en lo singular y en lo anecdótico- e intenta eludir la subordinación de lo micro a lo macro; por el contrario, considera que lo local tiene su especificidad, por lo que no es un mero reflejo

${ }^{66}$ CAMARERO, Hernán y HERRERA, Carlos “El Partido Socialista en Argentina...", cit., p. 67.

${ }^{67}$ Esto fue señalado para el caso de los partidos franceses por FRETEL, Julien y LEFEBVRE, Rémi "Retour sur un lieu commun historiographique: la faiblesse des partis politiques en France", en Journées AFSP "Science politique/Histoire", París, 4 al 6 de marzo de 2004, pp. 2-4. Disponible en http://www.afsp.msh-paris.fr [último acceso: 18/4/2016]. También otros autores observaron la tendencia de los estudiosos de la política a dar primacía a los aspectos formales sobre los informales. O'Donnell señaló que la democracia frecuentemente es concebida por los académicos, especialmente por los politólogos, desde una visión teleológica y normativa del desarrollo institucional, el cual es entendido en términos de una creciente formalización -por ejemplo, en términos como el de "consolidación democrática"-. En cambio, el autor remarcó el importante grado de la institucionalización de las reglas informales en Latinoamérica. O’DONNELL, Guillermo "Otra institucionalización", en Ágora, núm. 5, Buenos Aires, invierno de 1996, pp. 5-28. Otras investigaciones pusieron de relieve la importancia de la organización informal en el funcionamiento de los partidos políticos latinoamericanos, dada la importante distancia entre su organización formal y su funcionamiento real. FREIDENBERG, Flavia y LEVITSKY, Steven "Organización informal de los partidos en América Latina", en Desarrollo Económico, núm. 184, Buenos Aires, 2007, pp. 539-568.

${ }_{68}$ Planteos recientes en este sentido fueron recuperados por FERREYRA, Silvana "Socialismo en el interior. Socialismo al interior. Prácticas partidarias, cultura política y sociabilidades a "ras de suelo" en el Partido Socialista de la Argentina", en Dossier $N^{\circ} 74$ del Programa Interuniversitario de Historia Política, 2015, pp. 1-6. Disponible en http://historiapolitica.com/dossiers [último acceso: $18 / 4 / 2016]$.

${ }^{69}$ MAN, Ronen "La microhistoria como referente teórico-metodológico. Un recorrido por sus vertientes y debates conceptuales", en Historia Actual Online, núm. 30, Cádiz, 2013, pp. 167-173. Disponible en: http://www.historia-actual.org [último acceso: 14/11/2016] 
que solo sirve para confirmar lo investigado en otras escalas sino que busca dialogar con ellas, cuestionando y matizando ideas instaladas en la escala "nacional". ${ }^{70}$ En este sentido, la recuperación de la multiplicidad de sentidos y prácticas nativas analizadas a ras de suelo permite comprender problemas de alcance general a partir de experiencias localmente situadas, evitando preconceptos y generalizaciones etnocéntricas que operan como obstáculo epistemológico para la comprensión de lo social. ${ }^{71}$

De esta manera, se problematizaron ideas instaladas en la historiografía sobre el socialismo, como el alcance de la disciplina y de las prácticas políticas cívicas. Así, se señaló la existencia de tensiones entre la figura del militante y la del jugador, ya que entre las prácticas de ocio de la izquierda antifascista del interior bonaerense en la década de 1930 podían encontrarse actividades que eran consideradas un pasatiempo frívolo y superfluo, como el fútbol, o directamente una conducta inmoral, como las apuestas. ${ }^{72}$ También se destacó la existencia de prácticas mezquinas, faccionalistas y aprogramáticas -alejadas de la disciplina que caracterizaría a los socialistas- a partir del análisis de las prácticas implementadas por los referentes barriales porteños en la disputa por el control de los centros en el conflicto que dio origen al Partido Socialista Independiente en 1927. ${ }^{73}$ Asimismo, se evidenció el fortalecimiento de la inserción territorial socialista gracias al intercambio de bienes y servicios con asociaciones intermedias mediante militantes que participaban en su dirección prácticas que a otras fuerzas políticas le habían valido el calificativo de clientelares-. ${ }^{74}$

Nuestra investigación continúa el derrotero trazado por dichas investigaciones. Así, a través del análisis en escala microanalítica de las formas

\footnotetext{
${ }^{70}$ SERNA, Justo y PONS, Anaclet "En su lugar. Una reflexión sobre la historia local y el microanálisis", en Contribuciones desde Coatepec, núm. 4, Toluca, 2003, pp. 35-56.

${ }^{71}$ FREDERIC, Sabina y SOPRANO, Germán "Introducción", en Cultura y política en etnografías sobre la Argentina, Universidad Nacional de Quilmes, Bernal, 2005, pp. 11-65.

72 BISSO, Andrés "Apuntes sobre militancia, política, ocio y sociabilidad a través de la experiencia de izquierda y antifascista en el interior de la provincia de Buenos Aires en la época de la restauración conservadora (1932-1943)", en Anuario del Instituto de Historia Argentina, núm. 7, La Plata, 2007, pp. 135-153.

73 PÉREZ BRANDA, Pablo "Los centros socialistas y sus dirigentes durante la crisis partidaria de 1927. El nacimiento del Partido Socialista Independiente", en Partidos y micropolítica. Investigaciones históricas sobre partidos políticos en la Argentina del siglo XX, Suárez, Mar del Plata, 2011.

${ }^{74}$ FERREYRA, Silvana “¿`Prescindencia' o 'clientelismo'? Los vínculos entre el Partido Socialista Democrático y el mundo asociativo (1958-1966)", en Jornadas Académicas El asociacionismo en la Argentina del siglo XX, Buenos Aires, 22 y 23 de noviembre de 2012. Ferreyra también observó que la historiografía de la transición democrática estableció cierto sentido común sobre las formas de hacer política, vinculando la autonomía asociativa al socialismo y el clientelismo al peronismo, formas de acción política que recibieron una valoración positiva en el primer caso, y negativa en el segundo.
} 
de hacer política de los afiliados del Centro Socialista de Bahía Blanca a comienzos del siglo $\mathrm{XX}$, observamos ciertas prácticas $\mathrm{y}$ dinámicas institucionales que nos llevaron a problematizar determinadas ideas instaladas sobre el PS. Por ejemplo, detectamos entre los afiliados altos índices de morosidad y ausentismo asambleario, escaso compromiso con las actividades partidarias (como fiscalización de mesas electorales y distribución de propaganda) y numerosos conflictos de índole meramente personal, lo que nos permitió relativizar la férrea disciplina de la que se jactaban los socialistas. También advertimos que el centralismo partidario encontraba obstáculos y resistencias, ya que si bien el CE y la Federación Socialista Bonaerense pretendían coordinar la propaganda y las finanzas partidarias, los centros conservaban importantes márgenes de autonomía tanto en la organización de las campañas electorales como en la decisión de cómo y cuándo abonar sus cotizaciones a los organismos centrales. ${ }^{75}$

\section{Reflexiones finales}

En el presente trabajo hemos intentado repensar las concepciones académicas sobre los partidos políticos de las ciencias sociales en general y de la historia política en particular. En tal sentido, analizamos las concepciones nativas de los dirigentes del PS sobre los partidos políticos modernos y las concepciones académicas, observando que estas compartieron puntos en común con aquellas dado que figuras destacadas del campo se identificaban políticamente con el socialismo y desde dicha pertenencia construyeron una mirada normativa (socialdemócrata) sobre cómo debían ser y funcionar los partidos. Mientras que los dirigentes socialistas de comienzos de siglo XX concebían su partido como una institución moderna que conformaba ciudadanos conscientes y racionales, que participaban en la sociedad civil y tomaban sus decisiones políticas en base al análisis de los programas y la organicidad de los partidos, ubicaban a sus adversarios en el universo de la "política criolla", entendido como un ámbito en el que las carencias educativas y culturales de los individuos les impedían elegir racionalmente y los hacían más propensos a las influencias de las prácticas tradicionales, como el personalismo y el clientelismo. Una oposición dicotómica similar se daría más tarde en el campo académico argentino, a través de un esquema clave para interpretar las formas de hacer política, que estableció una

\footnotetext{
75 Hemos presentado avances de investigación en CABEZAS, Gonzalo "La propaganda socialista en el interior. Liderazgos y redes en la construcción partidaria a principios del siglo $X^{\prime \prime}$, en XV Jornadas Interescuelas/Departamentos de Historia, Universidad Nacional de la Patagonia San Juan Bosco, 16 al 18 de septiembre de 2015. Disponible en http://historiapolitica.com [último acceso: 18/4/2016]; CABEZAS, Gonzalo "La norma y la práctica en el centro socialista de Bahía Blanca: afiliaciones, cotizaciones, bajas y renuncias (1911-1919)", en Anuario de la Escuela de Historia (Virtual), Córdoba, núm. 6, 2014, pp. 71-89. Disponible en http://revistas.unc.edu.ar [último acceso: 18/4/2016].
} 
antinomia entre prácticas y agrupaciones tradicionales y modernas, enfatizando los aspectos organizacionales y orgánico-programáticos como los componentes propios de un partido político moderno.

Si bien hacia la década de 1990 distintos trabajos sobre las prácticas políticas de radicales y conservadores de comienzos de siglo $\mathrm{XX}$ permitieron repensar fenómenos como el caudillismo, el personalismo y el clientelismo como parte de la política moderna, la imagen del PS como el modelo de partido político permaneció incólume hasta recientemente. El desarrollo de los estudios sobre las formas de hacer política socialista ha abierto una línea de investigación que permite no solo construir un distanciamiento crítico de visiones normativas cuyos presupuestos no se manifiestan explícitamente, sino también sortear los obstáculos epistemológicos que dificultan la comprensión histórica y situada de los fenómenos analizados. Esto ha permitido discutir características clave de la concepción académica del PS y que han sido insuficientemente contrastadas empíricamente, como la férrea disciplina de los afiliados y el centralismo partidario.

Bahía Blanca, abril de 2016 